\title{
Exploring patients perceptions of accessing electronic health records: Innovation in healthcare
}

Sofie Wass, Vivian Vimarlund and Axel Ros

The self-archived postprint version of this journal article is available at Linköping University Institutional Repository (DiVA):

http://urn.kb.se/resolve?urn=urn:nbn:se:liu:diva-154991

N.B.: When citing this work, cite the original publication.

Wass, S., Vimarlund, V., Ros, A., (2019), Exploring patients perceptions of accessing electronic health records: Innovation in healthcare, Health Informatics Journal, 25(1), 203-215.

https://doi.org/10.1177/1460458217704258

Original publication available at:

https://doi.org/10.1177/1460458217704258

Copyright: SAGE PUBLICATIONS INC

https://uk.sagepub.com/ 


\title{
Exploring patients' perceptions of accessing electronic health records: Innovation in healthcare
}

\author{
Sofie Wass ${ }^{1}$, Vivian Vimarlund ${ }^{2}$ and Axel Ros ${ }^{3}$ \\ ${ }^{1}$ Jönköping International Business School, Jönköping University, Sweden \\ 2 Jönköping International Business School, Jönköping University, Sweden; \\ Linköping University, Sweden \\ ${ }^{3}$ School of Health and Welfare, Jönköping University, Sweden
}

\begin{abstract}
The more widespread implementation of electronic health records (EHRs) has led to new ways of providing access to healthcare information, allowing patients to view their medical notes, test results, medicines, etc. In this paper, we explore how patients perceive the possibility to access their EHR online and whether this influences patient involvement. The study includes interviews with nine patients and a survey answered by 56 patients. Our results show that patients perceive healthcare information to be more accessible and that EHR accessibility improves recall, understanding and patient involvement. However, to achieve the goal of involving patients as active decision-makers in their own treatment, EHRs need to be fully available and test results, referrals and information on drug interactions need to be offered. As patient access to EHRs spreads, it is important to gain a deeper understanding of how documentation practices can be changed to serve healthcare professionals and patients.
\end{abstract}

Keywords: ehealth, electronic health records, healthcare information, healthcare service innovation and IT, patient access

Published in Health Informatics Journal

Volume: 25 issue: 1 , page(s): 203-215

Article first published online: April 30, 2017; Issue published: March 1, 2019

https://doi.org/10.1177/1460458217704258 


\section{INTRODUCTION}

Digital technology and digital platforms that support the distribution and exchange of information have enabled the digitalization of processes that were previously supported by analogue tools. Digitalisation is also assumed to reduce communication costs and facilitate collaboration across traditional organisational boundaries. ${ }^{1}$ Within the healthcare sector, the progress in digital technology and the growing amount of digital health information have led to a change in the delivery of healthcare information within and across organisations and between patients and professionals. ${ }^{2}$ One example of the change from analogue to digital processes is the provision of patient access to electronic health records (EHRs). In the past, health records were reserved for healthcare professionals ${ }^{3}$, but the more widespread implementation of EHRs and patient portals has led to new ways of making healthcare information accessible to patients. Legal efforts such as the Federal Health Insurance Portability and Accountability Act of 1996 (HIPAA) and directives such as the eHealth Action Plan have opened up for these new patient services. Predecessors within the field include the OpenNotes Project in the U.S. ${ }^{4-6}$ and the SUSTAIN project in Europe. ${ }^{7}$ EHRs are now available online to patients, allowing them to access medical information concerning treatments, medicines, test results etc.

The development within the area has been possible due to the increased implementation and renewal of existing services and innovation in both communication and interaction between patients and healthcare professionals. New services or renewal of existing services, that are put into practice, can be defined as service innovations. Research on innovation traces back almost a century, ${ }^{8}$ but the term "innovation" and how it is defined still varies. Traditionally, it is viewed as a novel combination of new and existing resources. ${ }^{8}$ The $\mathrm{OECD}^{9}$ describes innovation as a product (including service), process, marketing method or organizational method that is put into practice. As for service innovation, it is argued that it is difficult to apply these four different types of outcomes, as services are both products and processes. ${ }^{10}$ Service innovation has been defined as something novel that provides change and is put into practice and that offers value on several levels. ${ }^{11}$ Although there is a need to study and understand the emergence of service innovations, i.e., the innovation process, ${ }^{10}$ it is equally important to understand the outcomes of such processes. ${ }^{11,12}$ Therefore, we focus on patient outcomes of the use of a service innovation, patients' online access to EHRs.

In this article, we present the results of an exploratory study on patients' perceptions of accessing their EHR online and the resulting effects on patient involvement. The knowledge obtained can be used to design longitudinal studies to follow up and evaluate the effects of service innovations ${ }^{1}$ such as patient access to EHRs. Patient involvement, in this paper, refers to involvement in decision-making, i.e. how patients increase their involvement in treatments decisions, changing the role of the patient from a passive patient to an informed and engaged consumer of services. ${ }^{13}$

\section{PREVIOUS RESEARCH}

Previous research on the effects of providing patient access to health records and EHRs has been reported in both literature reviews and research studies. A review on patient access to health records performed in 2003 focused on the effects of facilitating patient access to health records. The review shows that prior research has mainly focused on three areas: the effects on patients, the patientphysician relationship and medical practice. ${ }^{14}$ The effects on the patients include improvements in

\footnotetext{
1 Due to a significantly improved service and process $^{9}$ we define the new service, patient access to EHRs, as a service
} innovation. 
adherence, patient empowerment and patient education, e.g., recall and understanding of medical information. In addition, there are modest improvements in patient-physician communication, although patients find parts of the medical information difficult to understand. Nonetheless, few patients find the information confusing or upsetting. ${ }^{14}$

Similar issues have been found in more recent studies on the OpenNotes Project, which started in 2010 when 100 primary care physicians began digitally sharing notes with their patients. Studies on the OpenNotes Project report benefits such as increased adherence and compliance, ${ }^{4,15}$ feeling more in control of one's care ${ }^{4}$ and increased patient participation. ${ }^{16}$ OpenNotes was shown to enhance patients' understanding and recall of health information, ${ }^{4}, 16,17$ improve trust and communication in the patient-physician relationship ${ }^{16,17}$ and increase patient-centeredness. ${ }^{17}$ Some patients reported privacy concerns, but few stated that the notes caused confusion, worry or offense. ${ }^{4}$ Vodicka et al. ${ }^{18}$ assert that even if patients have concerns about privacy issues, the benefits of accessing health records seem to outweigh the perceived risks. In the end, patients have asked for more widespread access to EHRs. ${ }^{17}$

\section{PATIENT ACCESS TO EHRS IN SWEDEN: FROM PAPER TO ONLINE}

In Sweden, EHRs in the primary care were developed in the 1990s. This development was possible due to the public financing of healthcare, which provided the regions the financial capacity needed to support the implementation of these systems in larger as well as smaller care centres. ${ }^{19}$ This advancement was followed by the implementation of EHRs in hospitals, ${ }^{20}$ which followed a similar pattern as countries like the U.S., the United Kingdom and Denmark, in which the implementation was often driven by government initiatives. ${ }^{21}$ It was not until 2010, that EHRs were fully implemented for professionals across the entire Swedish healthcare system, including primary care, hospitals and psychiatric care. ${ }^{22}$ Prior to this, computer-based patient records had been implemented in local units and clinics to reduce costs and improve quality of patient care. ${ }^{3,23}$ Since the 1980s, Swedish patients have had the right to request a printed copy of parts of their health record ${ }^{24,25}$ but with the expansion of EHRs discussions on online access to healthcare information started. In 2012, Uppsala County Council was the first healthcare provider in Sweden to implement online access to EHRs for all its patients. ${ }^{29}$ In 2013, the Swedish Ministry of Health and Social Affairs presented a report that noted the need for a new patient legislation that sought to empower patients. ${ }^{26}$ In the report, it is stated that patients need access to information to be empowered and to make health-related decisions. According to the report, it is assumed that a more informed patient will feel less anxious and more in control. ${ }^{26}$ The report further asserts that the patient should have access to information about his or her healthcare status, different procedures, expected waiting time of healthcare, course of treatment, complications and follow-up care. ${ }^{26}$

Based on the report, Region Jönköping County decided to give all patients, aged 18 years or older, online access to their EHRs. ${ }^{27}$ The region decided on a "big bang" approach towards the implementation of patient access to EHRs and provided limited information in the media to patients about the new opportunity. The service was implemented across all care units in February 2015 apart from the departments of Psychiatry and Habilitation. Information from the EHR is made accessible via a national platform for eHealth. The platform enables integration between services and information systems by standardizing and sharing information between different healthcare actors. ${ }^{28}$ The possibility to access the EHR is optional, but all patients have the option to access the information through a secure log-in at the national patient portal "Healthcare Guide 1177" (www.minavardkontakter.se). Patients $\log$ in to the portal with the same electronic ID that they use for banking and other government e-services (www.bankid.com). 
Today, patients can access their EHR in real time and see and read the information there, including medical notes, diagnoses and vaccinations. The information shown is dated back to July 1, 2014, while older medical notes can be requested and received on paper. Healthcare professionals have 14 days, after documentation of the event, to confirm and if needed correct the medical notes before they become accessible to the patient. However, after 14 days, all notes are made accessible regardless of whether they have been confirmed. Patients can decide to share their EHR with other persons, and parents can access their children's EHR until they turn thirteen, due to national regulations. Patients are allowed to cancel their own access to the EHR at any time. Patients are not notified about new entries in the EHRs. The information included in the EHR is presented as an integrated record in which data are accessible chronologically, with every point of care organized by time and date. ${ }^{29}$ An overview of the service is presented in figure 1.

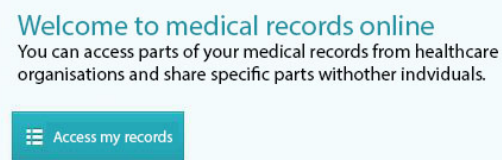

Figure 1: Overview of the service. During the time of the study, medical notes, vaccinations and diagnoses were accessible to the patients.

The expected effects of the service innovation include increased patient involvement, a better understanding of healthcare information and the ability for patients to be better prepared before an appointment. ${ }^{30}$ Patient access to EHRs is also believed to enhance communication, patient safety, and adherence and provides patients the opportunity to identify and correct errors. ${ }^{31}$ During the time of the study, patients' online access to the EHR had been implemented for 14 months.

\section{METHODS}

In the first step, before developing the survey to be distributed to patients in the Jönköping region, we reviewed the previous literature on patient perceptions of access to medical notes. ${ }^{4,17,18,32-34}$ This review provided us with knowledge of how previous studies had been designed. In a second step, we conducted interviews with nine patients to identify the major perceived benefits and worries related to patients' online access to EHRs and to ensure that they were included in the survey.

The patients interviewed were recruited at the county hospital in the region and were later contacted by email to agree on a time to conduct the interview at the hospital. Four of the respondents were women and five were men, aged between 34 and 83 and all had accessed their EHR when the study was performed. During the interviews, the respondents were asked questions regarding the patients' use of the EHR service, the benefits and drawbacks of accessing the EHR, improvements in the patient-physician communication and suggestions for further functions to be added to the service. The interviews were recorded and subsequently transcribed verbatim. The first author reviewed the transcripts of the interviews and identified themes focusing on the benefits, risks and expectations of accessing the EHR. The interviews were analysed using inductive content analysis 
as presented by Graneheim and Lundman ${ }^{35}$ which is a systematic way of describing and analysing verbal communication. ${ }^{36}$ The themes were derived from the interviews by focusing on sentences or paragraphs that were related in content. These sentences were then shortened and labelled with a code. Finally, the codes were compared and unified into themes. The themes were transformed into survey questions, and items on patient characteristics were added to the survey. The survey was reviewed by five patients and was revised according to the feedback received.

The survey was distributed to patients at three different sites in the Region of Jönköping County, Sweden: a primary care unit, a cardiology outpatient clinic and a urology outpatient clinic. The care unit and outpatient clinics were selected for survey distribution in order to reach patients who were currently in contact with the healthcare system. The survey was paper-based and was given to patients by a medical secretary upon registration for their visit along with an accompanying letter that stated that participation was voluntary and anonymous. The patients were eligible for the study if they had accessed their EHR via the patient portal. The completed survey could be returned in a box at the reception or sent by mail to the researchers if the patients preferred to complete it at home. No employees at the Region of Jönköping County had access to the individual answers. The distribution of surveys lasted for two weeks in May 2016, and because it was anonymous, no reminders were sent. In total, 56 patients completed the survey (12 patients declined to take part in the study and 24 did not return the survey).

The survey included questions regarding the use of the service, attitudes towards the benefits and downsides of accessing the EHR, and possible improvements to the services. For statements focusing on attitudes, we examined the results across a 5-level grade including "agree", "somewhat agree", "neither agree nor disagree", "somewhat disagree" and "disagree". The percentage of patients who agreed or disagreed to the statements was calculated for each question.

\section{RESULTS}

The following section addresses the results from the survey. The results are presented according to four sections that follow the structure of the survey: patients' perceived benefits of accessing the EHR, patient involvement, patients' worries and misunderstandings and possible improvements of the service.

The response rate for the survey was $61 \%(\mathrm{n}=56), 70 \%$ were men, ages ranged from $35-83$ years and $68 \%$ used the Internet several times a day $(n=53)$. Almost all of the patients viewed patient access to the EHR as a good or very good initiative $(94 \%, n=56)$. None of the patients considered it to be a negative initiative. The respondents were asked to choose the words they considered most suitable to describe the service. To do this, they were able to select from 23 "positive" and "negative" expressions (the list of alternatives is presented in appendix 1) and were also able to list additional words. The respondents answered that they would almost exclusively use expressions that were positive in nature, with the most common terms being as follows: trustworthy service, time saving, a citizen's right and easily accessible information (for details, see Table 1). 
Table 1: Expressions that the respondents would use to describe the service $(n=45)$.

\begin{tabular}{|c|c|c|c|c|c|}
\hline Rank & Expressions & $\%(n)$ & Rank & Expressions & $\%(n)$ \\
\hline 1 & Trustworthy service & $70 \%(31)$ & 8 & Openness towards citizens & $44 \%(20)$ \\
\hline 2 & Time saving & $64 \%(29)$ & 9 & Enables participation & $44 \%(20)$ \\
\hline 3 & A citizen's right & $62 \%(28)$ & 10 & Enables responsibility & $42 \%(19)$ \\
\hline 4 & $\begin{array}{l}\text { Easily accessible } \\
\text { information }\end{array}$ & $60 \%(27)$ & 11 & The patient can influence & $33 \%(15)$ \\
\hline 5 & Easy to navigate & $51 \%(23)$ & 12 & Difficult to navigate & $7 \%(3)$ \\
\hline 6 & $\begin{array}{l}\text { Secure information } \\
\text { management }\end{array}$ & $49 \%(22)$ & 13 & Undeveloped service & $4 \%(2)$ \\
\hline 7 & Rich with information & $47 \%(21)$ & 14 & $\begin{array}{l}\text { Creates } \\
\text { misunderstandings }\end{array}$ & $2 \%(1)$ \\
\hline
\end{tabular}

\section{BENEFITS OF ACCESSING EHRS}

To identify patients' perceived benefits of accessing the EHR, the respondents were asked to judge whether they agreed to five statements (figure 2 and Appendix 2, Table 3 for details). Almost all patients stated that it was easier to access information (96\%), to remember what was said during an appointment (90\%) and $72 \%$ stated that they were more or somewhat more prepared. The respondents expressed that the access to the EHR facilitated the understanding of what was documented, $72 \%$ stated that it was easier to discuss what was being documented in the EHR and $80 \%$ stated that it was easier to coordinate what was being documented.

The service makes it easier to...

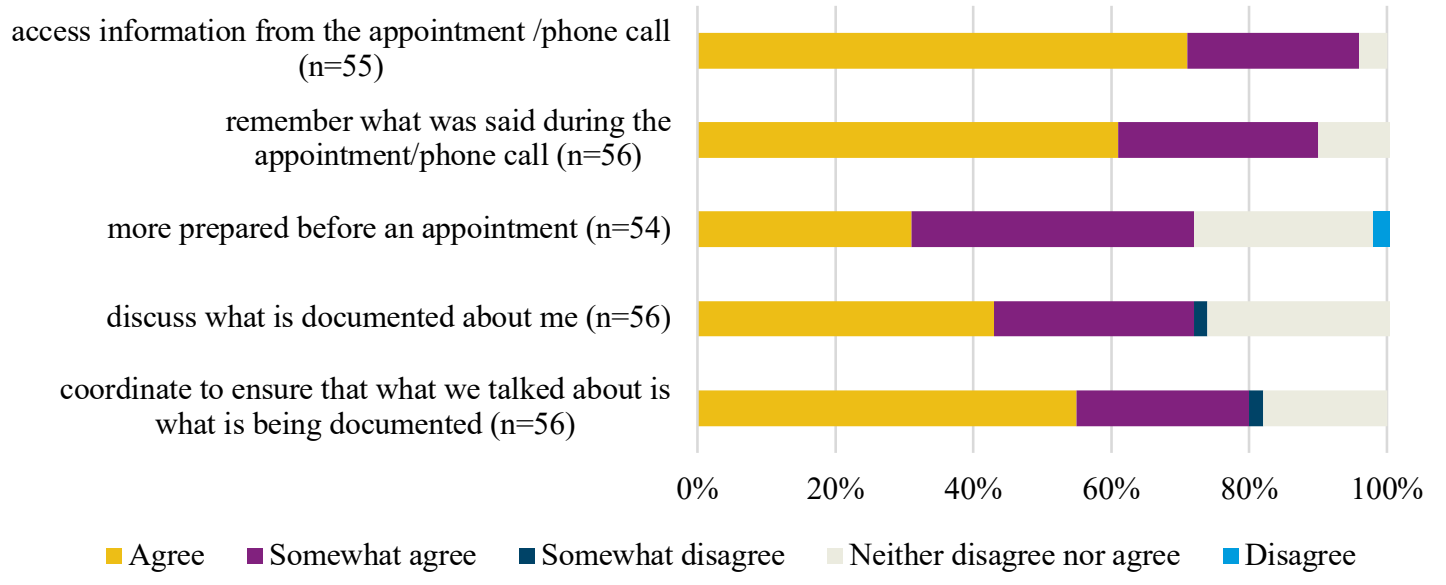

Figure 2: Patients' perceived benefits of accessing the EHR.

\section{PATIENT INVOLVEMENT}

The perceptions regarding patient involvement showed that $81 \%$ agreed or somewhat agreed that the service made them more involved in their treatment, and $70 \%$ stated that they were more likely to follow the advice given by healthcare professionals. In addition, $76 \%$ agreed or somewhat agreed that the service made it easier to take responsibility for their care, while $62 \%$ stated that it was easier to more actively affect their own care. $89 \%$ perceived it easier to understand what was said 
during the appointment and $82 \%$ of the patients agreed or somewhat agreed that the service made it easier to talk to healthcare professionals about their situation (figure 3 and Appendix 2, Table 4 for details).

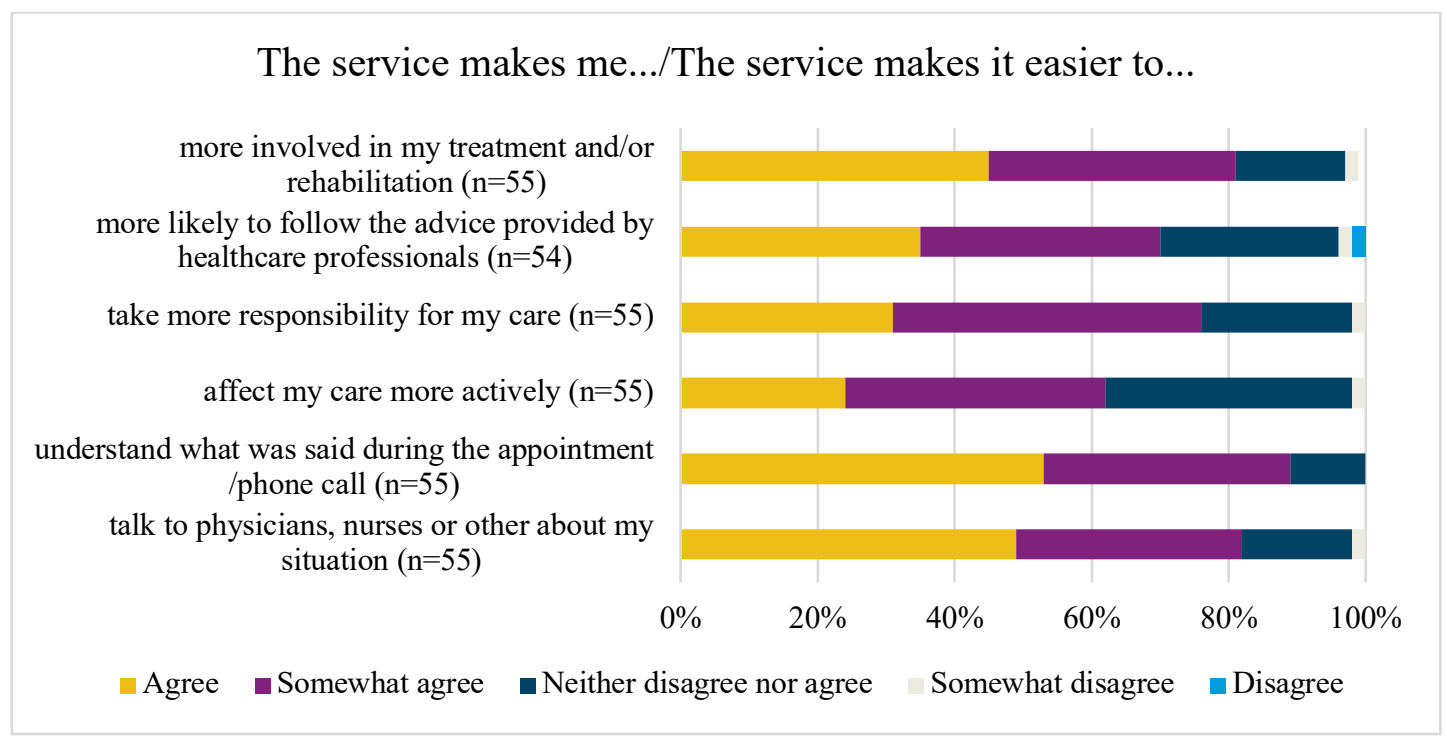

Figure 3: Patient perceptions regarding patient involvement.

\section{WORRIES AND MISUNDERSTANDINGS}

None of the respondents tended to misunderstand the information in the EHR and 58\% somewhat disagreed or disagreed to the statement. Only $11 \%$ and $9 \%$ of the patients agreed or somewhat agreed that they became worried or upset about the information in the EHR (Figure 4, Appendix 2 , Table 5 for details). In a follow-up question, $70 \%$ of the respondents expressed that some of the information in the EHR was difficult to understand. This information included medical terms $(61 \%)$ and abbreviations (32\%).

\section{The service has resulted in that I...}

misunderstand the information in my health record $(n=55)$

become worried about the information that can be read $(n=56)$

become upset about the information that can be $\operatorname{read}(n=56)$

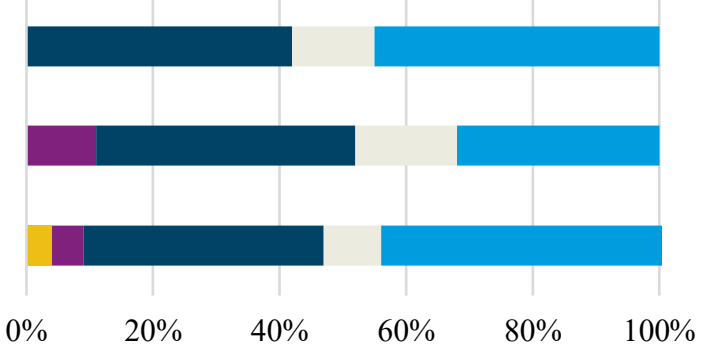

$\square$ Agree $\square$ Somewhat agree $\square$ Neither disagree nor agree $\quad$ Somewhat disagree $\square$ Disagree

Figure 4: Patient perceptions regarding worries and misunderstandings.

\section{IMPROVEMENTS TO THE SERVICE}

To determine the potentially valuable improvements to the EHR for patients, the respondents were asked to judge between seven predefined functionalities (presented in Table 2). They could also suggest other functionalities that were not listed. The top three preferred improvements of the service included information on test results $(85 \%)$, access to referrals $(61 \%)$ and information on the interactions between different drugs (46\%). 
Table 2: Assessment of proposed EHR functionalities.

\begin{tabular}{lll}
\hline Rank & $\begin{array}{l}\text { Functionalities selected in the top three by the } \\
\text { respondents }(\mathrm{n}=46) .\end{array}$ & $\%(\mathrm{n})$ \\
\hline 1 & Test results & $85 \%(39)$ \\
2 & Referrals & $61 \%(28)$ \\
3 & Interactions between different drugs & $46 \%(21)$ \\
4 & Medical records dated before 2014 & $35 \%(16)$ \\
5 & Reminders about new information in the EHR by SMS or & $22 \%(10)$ \\
& e-mail & $15 \%(7)$ \\
6 & The ability to report errors in the EHR & $13 \%(6)$ \\
\hline
\end{tabular}

\section{DISCUSSION}

In this article, we focus on how patients perceive the ability to access their own electronic health record online and whether the service innovation influences patient involvement. Overall, the patients report patient access to EHRs to be a good initiative. The results show, that the possibility to access the EHR increases information accessibility and improves patients' ability to understand and recall what was said during an appointment. These results are consistent with similar previous studies, with Delbanco et al. ${ }^{4}$ identifying benefits such as a greater understanding of visits and improved recall of healthcare plans. Esch et al. ${ }^{17}$ as well as Rexhepi et al. ${ }^{37}$ also reported that patients used medical notes to refresh their memory and to confirm their understanding. The results also seem to show that patients' relationship with healthcare professionals is improved, as it is easier to talk about their health with healthcare professionals and to discuss and coordinate what is documented. One of the most important outcomes of this study is the fact that patients feel more involved in their treatment, which is one dimension of patient involvement. ${ }^{13}$ Moreover, patients report that patient access to the EHR enhances responsibility-taking for their own care and adherence to healthcare professionals' advice. These outcomes are consistent with studies performed in projects like the OpenNotes project ${ }^{4,17}$ and in a study on EHRs with veterans. ${ }^{16}$

Although there are previous reports on patient concerns regarding security and privacy in relation to EHRs, ${ }^{18,38,39}$ the results show that the patients consider the service to be trustworthy and a secure way of managing health information. In our study, few patients reported being worried or upset about the information provided. However, the results show that even though patients do not misunderstand the information in the EHR, the majority find medical terms and abbreviations difficult to understand. EHRs were originally developed to increase quality of care and support practitioners and healthcare professionals. ${ }^{3}$ The political aim of providing patient access to EHRs is to increase patient involvement. To achieve the goal to fully involve patients as active decisionmakers in their own treatment, it will be necessary to study how documentation practices can be changed to serve healthcare professionals and patients. ${ }^{39}, 13$ The development of new documentation practices also needs to be complemented with the explanation of abbreviations and medical terms. This is consistent with previous research on service innovation, which argues that there is a need to not only offer new value propositions to the customer but also to transform organisational practices, structures and roles. ${ }^{40-43}$ This includes the roles of employees as well as of the service users. ${ }^{41}$ It is important to stress that medical documentation still needs to be expressed in such a way that healthcare can be safely performed by professionals.

Among the top three functionalities that the respondents wanted to add to the EHR were information on test results and access to referrals. This is routine patient-specific information that 
is related to the medical notes that patients can access today. The patients also valued information on the interactions between different drugs. Although this is not a typical EHR function, it would clearly provide patients additional benefits and increase the value offered by the patient portal. These are novel findings compared to those reported by Hoerbst et al. ${ }^{38}$ for instance, who identified electronic vaccination records, online information on hospitals and the management of appointments and reminders as the most favoured functionalities of an EHR. Currently, Swedish citizens partly have access to these functionalities through the patient portal, and more individual and healthcare-related services have been requested. According to the classification proposed by Prey et al., ${ }^{44}$ personalized decision support, such as information on drug interactions, is a more complex type of service that enables patient engagement to a higher degree.

By providing patients with online access to their EHR, the Region Jönköping County expected patients to identify and notify the healthcare provider about the need to correct errors in the EHR. ${ }^{31}$ However, our findings show no signs of any requests for amendments, the reason can be the lack of information on if and how patients can request changes to their records. If management expect this type of innovation effect, additional information needs to be provided to the patients. ${ }^{45}$

\section{CONCLUSION}

Although patients are central to healthcare, information systems have traditionally been developed and implemented for professionals with the aim to improve quality and safety and not for patients. ${ }^{3 \text {, }}$

${ }^{46}$ Providing patients with online access to their health records presents a new situation. The results show that patients perceive their healthcare information to be more accessible and that the additional accessibility saves time, enhances recall and understanding and increases patient involvement. Hence, we argue that patient access to EHRs provides an improved service delivery and process.

Patients' online access to EHRs seems to be a step towards changing the role of the patient by enabling access to and providing patients with information that has previously been disclosed or less accessible. According to this study, patients expressed that the access to the EHR improves patient involvement and the patient-professional relationship. However, to change the role of the patient from a passive receiver to an active engaged patient it is necessary to fully share medical records with patients and provide information on test results, the opportunity to monitor referrals and additional services such as information on drug interactions. As patient access to EHRs spreads, it is important to gain a deeper understanding of how the practice can adapt and change to better prepare and educate patients to enhance patient involvement. ${ }^{13}$ Currently, there seems to be a need to find alternatives that support patients who do not have a medical background or sufficient knowledge to interpret medical information. A deeper examination of these aspects will be important, especially for specific patient groups such as psychiatric patients and patients with other native languages.

Although this study was limited by the relatively small sample, we believe that our results provide insight into an understudied area of providing patients access to their EHRs in a setting outside of the U.S and the OpenNotes Project. Previous Swedish studies have, except for Rexhepi et al., ${ }^{37}$ mostly focused on the development and usability issues of this type of service, ${ }^{47}$ the public debate, ${ }^{48}$ privacy issues $^{49}$ and the attitudes of healthcare professionals. ${ }^{50}$

\section{Acknowledgements}

The authors express their appreciation to the individuals involved in the project and to xxx for assisting with the data collection. 
Declaration of conflicting interests

The authors declare no potential conflicts of interest with respect to the research, authorship, and/or publication of this article.

Funding

This research received no specific grant from any funding agency in the public, commercial, or not-for-profit sectors.

\section{REFERENCES}

1. Yoo Y, Boland RJ Jr, Lyytinen K, et al. Special Issue: Organizing for Innovation in the Digitized World. Organ Sci 2009; 20: 278-279.

2. McGowan JJ, Cusack CM and Bloomrosen M. The future of health IT innovation and informatics: a report from AMIA's 2010 policy meeting. $J$ Am Med Inform Assoc 2012; 19: 460467.

3. Haux R. Health information systems - past, present, future. Int J Med Inform 2006; 75: 268-281.

4. Delbanco T, Walker J, Bell SK, et al. Inviting Patients to Read Their Doctors' Notes: A Quasiexperimental Study and a Look Ahead. Ann Intern Med 2012; 157: 461-470.

5. Delbanco T, Walker J, Darer JD, et al. Open Notes: Doctors and Patients Signing On. Ann Intern Med 2010; 153: 121-125.

6. Feldman HJ, Walker J, Li J, et al. OpenNotes: Hospitalists' challenge and opportunity. $J$ Hosp Med 2013; 8: 414-417.

7. European Commission. Access to your health records - results of the SUSTAINS pilot. Report, 2014.

8. Schumpeter JA. The Theory of Economic Development: An Inquiry into Profits, Capital, Credit, Interest, and the Business Cycle. Cambridge: Harvard University, 1934.

9. OECD. Oslo Manual: Guidelines for collecting and interpreting innovation data. Report, France, 2005, p. 1-163.

10. Gallouj F and Weinstein O. Innovation in services. Res Policy 1997; 26: 537-56.

11. Toivonen M and Tuominen T. Emergence of innovations in services. Serv Ind $J$ 2009; 29: 887902.

12. Witell L, Snyder H, Gustafsson A, et al. Defining service innovation: A review and synthesis. J Bus Res 2016; 69: 2863-2872.

13. Snyder H and Engström J. The antecedents, forms and consequences of patient involvement: A narrative review of the literature. Int J Nurs Stud 2015; 53: 351-378.

14. Ross SE and Lin C-T. The Effects of Promoting Patient Access to Medical Records: A Review. $J$ Am Med Inform Assoc 2003; 10: 129-138.

15. Wright E, Darer J, Tang X, et al. Sharing Physician Notes Through an Electronic Portal is Associated With Improved Medication Adherence: Quasi-Experimental Study. J Med Internet Res 2015; 17: e226.

16. Woods SS, Schwartz E, Tuepker A, et al. Patient Experiences With Full Electronic Access to Health Records and Clinical Notes Through the My HealtheVet Personal Health Record Pilot: Qualitative Study. J Med Internet Res 2013; 15: e65.

17. Esch T, Mejilla R, Anselmo M, et al. Engaging patients through open notes: an evaluation using mixed methods. BMJ Open 2016; 6.

18. Vodicka E, Mejilla R, Leveille SG, et al. Online Access to Doctors' Notes: Patient Concerns About Privacy. J Med Internet Res 2013; 15: e208.

19. Kajbjer K, Nordberg R and Klein GO. Electronic Health Records in Sweden: From Administrative Management to Clinical Decision Support. In: History of Nordic Computing 3: 
Third IFIP WG 97 Conference, HiNC 3I (ed mpagliazzo J, Lundin P and Wangler B), Stockholm, Sweden, 18-20 October 2010. pp. 74-82. Berlin, Heidelberg: Springer Berlin Heidelberg.

20. Jerlvall L and Pehrsson T. eHealth in the county councils [in swedish]. Report, 2016, p. 1-26.

21. Boonstra A, Versluis A and Vos JFJ. Implementing electronic health records in hospitals: a systematic literature review. BMC Health Serv Res 2014; 14: 370.

22. Jerlvall L and Pehrsson T. eHealth in the county councils [in swedish]. Report, 2011, p. 1-55.

23. Clayton PD and van Mulligen E. The Economic Motivations for Clinical Information Systems. In: Proceedings of the AMIA Annual Fall Symposium, 1996, pp. 660-668.

24. 1177 The Healthcare Guide. The Health record [In Swedish], http://www.1177.se/Regler-ochrattigheter/Patientjournalen/ (2015, accessed 9 August 2016).

25. Patient Records Act [Patientjournalen], (1985:562).

26. The Swedish Ministry of Health and Social Affairs. Patientlag - delbetänkande av patientmaktsutredningen. Report, 2013.

27. Region Jönköping county. Annual budget with operational plan 2014 - long term plan 20152016 [In Swedish]. Report, Huskvarna: Elanders/NRS Tryckeri AB, 2013, p. 1-98.

28. Inera. Architecture and Infrastructure [In Swedish], http://www.inera.se/ARKITEKTUR-INFRASTRUKTUR/ (2015, accessed 20 June 2016).

29. Coiera E. Guide to health informatics. $3^{\text {rd }}$ ed. Boca Raton, Fla.: CRC Press, 2015.

30. Region Jönköping county. Prestudy on patient access to medical notes in the county of Jönköping [In Swedish]. Report, Qulturum, 2014, p. 1-20.

31. Jörhall C. Project: Patient access to medical notes [In Swedish]. Report, Region Jönköping county, 2014, p. 1-5.

32. Walker J, Leveille SG, Ngo L, et al. Inviting Patients to Read Their Doctors' Notes: Patients and Doctors Look AheadPatient and Physician Surveys. Ann Intern Med 2011; 155: 811-819.

33. Jackson SL, Mejilla R, Darer JD, et al. Patients Who Share Transparent Visit Notes With Others: Characteristics, Risks, and Benefits. J Med Internet Res 2014; 16: e247.

34. Leveille SG, Walker J, Ralston JD, et al. Evaluating the impact of patients' online access to doctors' visit notes: designing and executing the OpenNotes project. BMC Med Inform Decision Making 2012; 12: 1-10.

35. Graneheim UH and Lundman B. Qualitative content analysis in nursing research: concepts, procedures and measures to achieve trustworthiness. Nurs Educ Today 2004; 24: 105-112.

36. Krippendorff K. Content analysis : an introduction to its methodology. Thousand Oaks, Calif.: Sage 2004.

37. Rexhepi H, Åhlfeldt R-M, Cajander $\AA$, et al. Cancer patients' attitudes and experiences of online access to their electronic medical records: A qualitative study. Health Inform J 2016; Special Issue: $1-10$.

38. Hoerbst A, Kohl CD, Knaup P, et al. Attitudes and behaviors related to the introduction of electronic health records among Austrian and German citizens. Int J Med Inform 2010; 79: 81-89. 39. Beard L, Schein R, Morra D, et al. The challenges in making electronic health records accessible to patients. J Am Med Inform Assoc 2012; 19: 116-120.

40. Kindström D and Kowalkowski C. Service innovation in product-centric firms: a multidimensional business model perspective. J Bus Ind Marketing 2014; 29: 96-111.

41. Edvardsson B, Gustafsson A, Sandén B, et al. New service development and innovation in the new economy. Lund: Studentlitteratur, 2000.

42. Sundbo J. Management of Innovation in Services. Serv Ind J 1997; 17: 432-455.

43. Hertog Pd. Knowledge-intensive business services as co-producers of innovation. Int J Innov Manage 2000; 4: 491-528. 
44. Prey JE, Woollen J, Wilcox L, et al. Patient engagement in the inpatient setting: a systematic review. $J$ Am Med Inform Assoc 2014; 21: 742-750.

45. Hanauer DA, Preib R, Zheng K, et al. Patient-initiated electronic health record amendment requests. J Am Med Inform Assoc 2014; 21: 992-1000.

46. Vimarlund V, Ljunggren $M$ and Timpka T. Implementation of computer-based patient records in primary care: the societal health economic effects. In: Proc AMIA Annu Fall Symp, Washington, U.S, 11-15 November 1996, pp. 503-507.

47. Scandurra I, Holgersson J, Lind T, et al. Development of patient access to electronic health records as a step towards ubiquitous public ehealth. Eur J ePractice. 2013; 20: 21-36.

48. Huvila I, Myreteg G and Cajander Å. Empowerment or anxiety? Research on deployment of online medical E-health services in Sweden. B Am Soc Inform Inf 2013; 39: 30-33.

49. Åhlfeldt R-M and Huvala I. Patient Safety and Patient Privacy When Patient Reading Their Medical Records. In: Safe and Secure Cities: 5th International Conference on Well-Being in the Information Society, WIS (ed Saranto K, Castrén M, Kuusela T, et al.), Turku, Finland, 18-20 August 2014, pp. 230-239. Cham: Springer International Publishing.

50. Ålander T and Scandurra I. Experiences of Healthcare Professionals to the Introduction in Sweden of a Public eHealth Service: Patients' Online Access to their Electronic Health Records. In: MEDINFO, Sao Paulo, Brazil, 2015, pp. 153-157. 


\section{APPENDIX 1}

$\square \quad$ Time saving

口 Time consuming

Easy to navigate

$\square$ Difficult to navigate

$\square$ Secure information management

$\square$ Insecure information management

Openness towards citizens

A trustworthy service

An unreliable service

$\square$ A citizen's right

口 An inappropriate investment

$\square$ Enables responsibility $\square$ Bureaucratic

口 A misprioritized investment

$\square$ Rich on information

$\square$ Enables participation

$\square$ Can be influenced by patients

$\square$ Undeveloped service

$\square$ Creates worries

口 Creates misunderstandings

$\square$ Stressful

Confuses the patient

$\square$ Easily accessible information

$\square \quad$ Other

$\square \quad$ Other

$\square$ Other 


\section{APPENDIX 2}

Table 3: Patient perceptions of the benefits of accessing the EHR.

\begin{tabular}{llllll}
\hline \multicolumn{5}{c}{ The service makes it easier to... } & \\
& $\begin{array}{l}\text { Agree } \% \\
(\mathrm{n})\end{array}$ & $\begin{array}{l}\text { Somewha } \\
\text { t agree } \% \\
(\mathrm{n})\end{array}$ & $\begin{array}{l}\text { Neither agree } \\
\text { nor disagree } \\
\%(\mathrm{n})\end{array}$ & $\begin{array}{l}\text { Somewha } \\
\mathrm{t} \text { disagree } \\
\%(\mathrm{n})\end{array}$ & $\begin{array}{l}\text { Disagree } \\
\%(\mathrm{n})\end{array}$ \\
\hline $\begin{array}{l}\text { Access information from the } \\
\text { appointment /phone call } \\
(\mathrm{n}=55)\end{array}$ & $71 \%(39)$ & $25 \%(14)$ & $4 \%(2)$ & - & - \\
\hline $\begin{array}{l}\text { Remember what was said } \\
\text { during the appointment/phone } \\
\text { call (n=56) }\end{array}$ & $61 \%(34)$ & $29 \%(16)$ & $11 \%(6)$ & - & - \\
\hline $\begin{array}{l}\text { More prepared for an } \\
\text { appointment (n=54) }\end{array}$ & $31 \%(17)$ & $41 \%(22)$ & $26 \%(14)$ & - & $2 \%(1)$ \\
\hline $\begin{array}{l}\text { Discuss what is documented } \\
\text { about me (n=56) }\end{array}$ & $43 \%(24)$ & $29 \%(16)$ & $27 \%(15)$ & $2 \%(1)$ & - \\
\hline $\begin{array}{l}\text { Coordinate to ensure that } \\
\text { what we talked about is what } \\
\text { is being documented (n=56) }\end{array}$ & $55 \%(31)$ & $25 \%(14)$ & $18 \%(10)$ & $2 \%(1)$ & - \\
\hline
\end{tabular}

Table 4: Patient perceptions regarding patient involvement.

\begin{tabular}{llllll}
\hline \multicolumn{5}{c}{ The service makes me... } & \\
& $\begin{array}{l}\text { Agree \% } \\
(\mathrm{n})\end{array}$ & $\begin{array}{l}\text { Somewha } \\
\mathrm{t} \text { agree } \% \\
(\mathrm{n})\end{array}$ & $\begin{array}{l}\text { Neither agree } \\
\text { nor disagree } \% \\
(\mathrm{n})\end{array}$ & $\begin{array}{l}\text { Somewhat } \\
\text { disagree } \\
\%(\mathrm{n})\end{array}$ & $\begin{array}{l}\text { Disagree } \% \\
(\mathrm{n})\end{array}$ \\
\hline $\begin{array}{l}\text { More involved in my } \\
\text { treatment and/or } \\
\text { rehabilitation (n=55) }\end{array}$ & $\begin{array}{l}45 \% \\
(25)\end{array}$ & $36 \%(20)$ & $16 \%(9)$ & $2 \%(1)$ & - \\
\hline $\begin{array}{l}\text { More likely to follow the } \\
\text { advice provided by } \\
\text { healthcare professionals } \\
\text { (n=54) }\end{array}$ & $\begin{array}{l}35 \% \\
(19)\end{array}$ & $35 \%(19)$ & $26 \%(14)$ & $2 \%(1)$ & $2 \%(1)$ \\
\hline $\begin{array}{l}\text { The service makes it } \\
\text { easier to... }\end{array}$ & & & & & \\
\hline $\begin{array}{l}\text { Take more responsibility } \\
\text { for my care (n=55) }\end{array}$ & $31 \%$ & $45 \%(25)$ & $22 \%(12)$ & $2 \%(1)$ & - \\
\hline
\end{tabular}




\begin{tabular}{llllll}
\hline $\begin{array}{l}\text { Affect my care more } \\
\text { actively (n=55) }\end{array}$ & $\begin{array}{l}24 \% \\
(13)\end{array}$ & $38 \%(21)$ & $36 \%(20)$ & $2 \%(1)$ & - \\
\hline $\begin{array}{l}\text { Understand what was said } \\
\text { during the appointment } \\
\text { phone call (n=55) }\end{array}$ & $53 \%$ & $36 \%(20)$ & $11 \%(6)$ & - & - \\
\hline $\begin{array}{l}\text { Talk to physicians, nurses } \\
\text { or other about my } \\
\text { situation (n=55) }\end{array}$ & $49 \%$ & $33 \%(18)$ & $16 \%(9)$ & $2 \%(1)$ & - \\
\hline
\end{tabular}

Table 5: Patient perceptions regarding worries and misunderstandings.

\begin{tabular}{llllll}
\hline \multicolumn{5}{c}{ The service has resulted in that I... } \\
& $\begin{array}{l}\text { Agree } \\
\%(\mathrm{n})\end{array}$ & $\begin{array}{l}\text { Somewh } \\
\text { at agree } \\
\%(\mathrm{n})\end{array}$ & $\begin{array}{l}\text { Neither agree } \\
\text { nor disagree } \\
\%(\mathrm{n})\end{array}$ & $\begin{array}{l}\text { Somewhat } \\
\text { disagree } \\
\%(\mathrm{n})\end{array}$ & $\begin{array}{l}\text { Disagree } \\
\%(\mathrm{n})\end{array}$ \\
\hline $\begin{array}{l}\text { Misunderstand the } \\
\text { information in my health } \\
\text { record (n=55) }\end{array}$ & - & - & $42 \%(23)$ & $13 \%(7)$ & $45 \%(25)$ \\
\hline $\begin{array}{l}\text { Become worried about the } \\
\text { information that can be read } \\
(\mathrm{n}=56)\end{array}$ & - & $11 \%(6)$ & $41 \%(23)$ & $16 \%(9)$ & $32 \%(18)$ \\
\hline $\begin{array}{l}\text { Become upset about the } \\
\text { information that can be read } \\
(\mathrm{n}=56)\end{array}$ & $4 \%(2)$ & $5 \%(3)$ & $38 \%(21)$ & $9 \%(5)$ & $45 \%(25)$ \\
\hline
\end{tabular}

